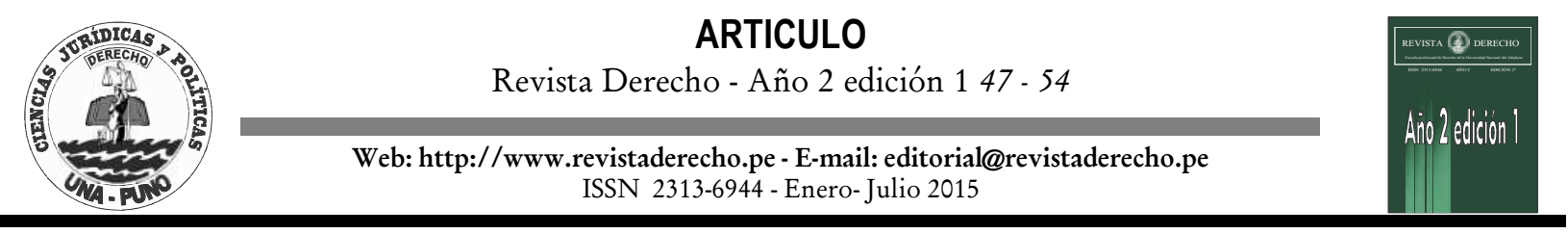

\title{
LA REPARACIÓN CIVIL CUANDO LA ACCIÓN PENAL HA PRESCRITO EN APLICACIÓN DEL ARTÍCULO 12 INCISO 3 DEL CÓDIGO PROCESAL PENAL
}

Wilfredo Chura Sotomayor*

* Bachiller de la Facultad de Ciencias Jurídicas y Políticas, Escuela Profesional de Derecho de la Universidad Nacional del Altiplano.

INFORMACIÓN DEL ARTICULO

Art. Recibido 08/02/15

Art. Aceptado 09/06/15

Publicado: 30/07/15

PALABRAS CLAVE:

* La acción penal * extinción de la acción penal *la prescripción

* la prescripción de la acción penal * la reparación civil * subsistencia de la reparación civil

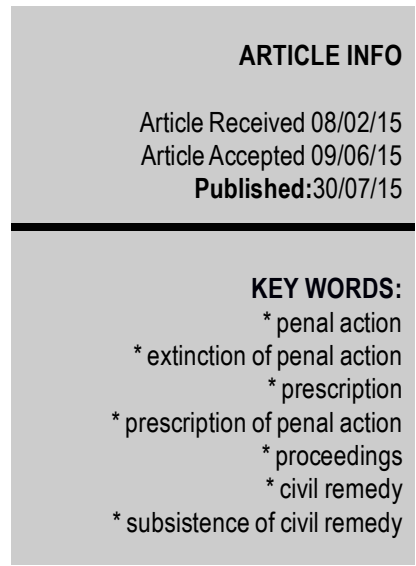

\section{RESUMEN}

Se analiza la aplicación del Artículo 12, Inciso 3 del nuevo Código Procesal Penal, que prescribe: «la sentencia absolutoria o el auto de sobreseimiento no impedirá al Órgano Jurisdiccional pronunciarse sobre la acción civil derivada del hecho punible válidamente ejercida, cuando proceda»; considerando que se han generado una serie de resoluciones pronunciándose respecto a la reparación civil, cuando la acción penal se ha extinguido por prescripción, trayendo consigo la vulneración de normas de la prescripción de la acción penal y el debido proceso; vulnerando lo establecido en el Artículo 100 del Código Penal que establece que «la acción civil derivada del hecho punible no extingue mientras subsiste la acción penal». El tipo de investigación jurídica corresponde al jurídico dogmático.

\section{CIVIL REMEDY WHEN PENAL ACTION HAS PRESCRIBED IN APPLICATION OF ARTICLE 12 INCISE 3 OF THE PENAL PROCEDURE CODE}

ABSTRACT
The present study analyzes the application of article 12 incise 3 of the new penal
procedure code that states: «the absolutory sentence or the dismissal notice will not
prevent the court decide on the civil action derived from the punishable act, where
appropriate.» From this statement the author make awareness that many resolutions
were made in relation to the civil remedy, when the prosecution has become extinct
by prescription, bringing with it the violation of the prescription of the criminal
action and due process standards, likewise, there is an infringement of the statement
of article 100 of the Penal Code which establishes that «the civil action derived from
the punishable act is not extinguished while the penal action subsists». The research
method corresponds to the legal dogmatic approach.

\section{ABSTRACT}

The present study analyzes the application of article 12 incise 3 of the new penal procedure code that states: «the absolutory sentence or the dismissal notice will not prevent the court decide on the civil action derived from the punishable act, where appropriate.» From this statement the author make awareness that many resolutions were made in relation to the civil remedy, when the prosecution has become extinct by prescription, bringing with it the violation of the prescription of the criminal action and due process standards, likewise, there is an infringement of the statement of article 100 of the Penal Code which establishes that «the civil action derived from method corresponds to the legal dogmatic approach. 


\section{INTRODUCCIÓN}

En el artículo se realiza el análisis de la reparación civil cuando la acción penal ha prescrito en aplicación del Artículo 12, Inciso 3 del Nuevo Código Procesal Penal; por ello, la reparación civil o resarcimiento del daño proveniente del delito puede ser objeto de pronunciamiento cuando la acción penal ha prescrito por parte de los jueces penales en aplicación del citado artículo, surge así la inquietud: ¿Puede el órgano jurisdiccional penal pronunciarse respecto a la reparación civil, cuando la acción penal ha prescrito en aplicación del Artículo 12 Inciso 3 del Nuevo Código Procesal Penal?; para ello, se ha planteado preguntas específicas para investigar ¿Cómo afecta la prescripción de la acción penal respecto a la reparación civil en proceso penal?, ¿¿De qué manera la prescripción de la acción penal impide al órgano jurisdiccional, la aplicación del Artículo 12 Inciso 3 del Nuevo Código Procesal Penal respecto a la reparación civil?; y, ¿Qué medidas debe considerarse para una correcta aplicación del Artículo 12 Inciso 3 del Nuevo Código Procesal Penal, cuando exista por medio una prescripción de la acción penal?.

El objetivo general de la investigación fue demostrar que el órgano jurisdiccional penal no puede pronunciarse respecto a la reparación civil cuando la acción penal haya prescrito; para ello, se analizo como regula en el Derecho Nacional y el Derecho comparado la vigencia de la reparación civil cuando la acción penal prescribe; establecer de qué manera vienen interpretando los jueces la regulación legal respecto a la vigencia de la reparación civil cuando la acción penal ha prescrito; $y$, proponer las medidas y criterios para una adecuada interpretación de la regulación que existe sobre la vigencia de la reparación civil en el proceso penal cuando la acción penal haya prescrito.

\section{MATERIALES Y MÉTODOS}

Es una investigación cualitativa, en razón de que se procedió mediante las técnicas del análisis y la observación a revisar doctrina, normas y expedientes que tengan que ver con la prescripción de la acción penal y la reparación civil. El tipo de investigación jurídica corresponde al jurídico dogmático, puesto que se busca dar una adecuada interpretación de la regulación que existe sobre la vigencia de la reparación civil en el proceso penal cuando la acción penal haya prescrito.

El ámbito de estudio se concentra en la legislación, normatividad y doctrina existente sobre la reparación civil cuando la acción penal prescribe, así como la doctrina jurisprudencial existente en referencia al tema de investigación

El universo de estudio es el la legislación, normatividad y doctrina existente sobre la reparación civil cuando la acción penal prescribe, así como la doctrina jurisprudencial existente en referencia al tema de investigación.

La muestra de estudio para el presente trabajo de investigación se determina en la legislación existente, así como se realizara la revisión de doctrina y jurisprudencias en relación a la presente investigación.

\section{DISCUSIÓN}

\subsection{La Vigencia de la Reparación Civil}

(Villegas Paiva E. A., 2013) Dice que en primer lugar se debe tomar en cuenta el Artículo 2001, Inciso 4 del Código Civil que establece que prescribe «salvo disposición diversa de la ley: A los dos años, la acción indemnización por responsabilidad extra contractual, y a su vez el Artículo 100 del Código Penal establece que la «acción civil derivada del hecho punible no extingue mientras subsista la acción penal».

(Castillo Alva, 2001)inidica que lo primero que debemos de señalar, es que el termino extinción a que hace referencia el citado artículo del Código Penal (CP) ${ }^{1}$ no hace referencia a la extinción de la acción civil en general, sino solamente a la extinción por prescripción de ésta cuando provenga de un hecho punible, para ser más exacto de un ilícito de apariencia delictiva. De acuerdo a ello, se tiene que el artículo 100 del Código Penal regula que la acción civil solo se extinguirá (prescripción) cuando la acción penal se extinga igualmente por prescripción bajo esa perspectiva (Salinas Siccha, 2009)indica que a efectos de la acción civil por responsabilidad extracontractual proveniente de una conducta delictiva, no es aplicable el inciso 4 del artículo 2001 del Código Civil, toda vez que por el principio de especialidad de aplicación de la ley hace aplicable el artículo 100 del Código Penal, de esta forma manifiesta (Revilla LLaza, 2009) que si producido el ilícito penal generador de daño, transcurren más de dos años (inciso 4 del artículo 2001 del Código Civil) sin que interrumpa la prescripción de la acción civil, ello no la extingue, pues el plazo de prescripción aplicable es de la acción penal (artículo 100 del Código Penal). Solo si transcurre el plazo de prescripción

1 En adelante entiéndase como: CP (Código Penal) 
extraordinaria de la acción penal (artículo 83 in fine del Código Penal) ininterrumpidamente la acción penal y, con ella la civil, fenecerán.

Asi mismo indica (Roy Freyre, 1979)que el artículo 100 del código penal dispones que la acción civil derivada de hecho punible no se extingue mientras subsiste la acción penal, por interpretación a contrario sensu del texto transcrito se concluye que la extinción de la acción penal, por cualquiera de las causales legalmente previstas, conlleva la cancelación de la acción civil para reclamar el pago de la respectiva reparación.

En tal razón lo manifestado por (Peña Cabrera Freyre, 2010) que indica que declarada prescrita la acción penal, en el procedimiento punitivo, se diría que la acción civil, también habría prescrito; lo que no es tanto así. La extinción de dicha pretensión, por el transcurso inevitable del tiempo, en lo concerniente a la acción penal, solo opera en la vía penal; quiere decir, esto que el actor civil o dígase la parte civil, cuenta con la vía expedita, para acudir a la tutela jurisdiccional efectiva, en la vía civil, en cuanto a la interposición de una demanda de daños y perjuicios. Es de verse que los plazos de prescripción en materia penal, pueden resultar en algunos casos, más cortos que los previstos en la vía civil (prescripción y caducidad), por lo tanto, resulta legítimo, que el hecho que la acción penal judicialmente declarada prescrita, no impida al afectado a recurrir al amparo de la tutela jurisdiccional efectiva, vía indemnización de daños y perjuicios, o pueda también que ambos procesos se estén tramitando paralelamente.

Lo cual sería contrario a lo establecido en el Código Procesal Penal y lo manifestado por (Guillermo Bringas, 2011) que indica que, se debe precisar que esta acumulación, considerando la naturaleza jurídica de la reparación civil y realizando una interpretación sistemática del ordenamiento jurídico vigente, no es obligatorio, sino que dependerá de la voluntad del agraviado. En este sentido, procederá la acumulación, siempre y cuando, el agraviado así lo decida, constituyéndose, para ese efecto, en actor civil. Es decir, la posibilidad de acumular las acciones debe entenderse solo como eso: una posibilidad, nunca como un acto obligatorio. Por ello es posible acudir a otra vía distinta a la penal con la finalidad de que el agraviado o perjudicado se procure la reparación civil correspondiente. Además el CPP en su artículo 12 inciso 1 , acorde con lo dicho, prescribe que «El perjudicado por el delito podrá ejercer la acción civil en el proceso penal o ante el orden jurisdiccional civil».
Lo que se debe concordar con el artículo 106 del mismo cuerpo normativo, que a la letra establece: «La constitución en actor civil impide que se presente demanda indemnizatoria en la vía extra-penal. El actor civil que se desiste como tal antes de la acusación fiscal no está impedido de ejercer la acción indemnizatoria en la otra vía», y mas aun con lo manifestado por (Gálvez Villegas T. A., 2012) al señalar que el artículo 92 del código penal y otras normas afines establecen que la reparación civil se establece conjuntamente con la pena, por lo que en caso de absolución-en los que no hay pena-, tampoco se podrá determinar la reparación civil.

Como se puede apreciar lo manifestado por (Peña Cabrera Freyre, 2010) de que la acción resarcitoria vale decir la acción civil sea inextinguible, quedaría desvirtuado por la postura de (Guillermo Bringas, 2011)así como con el código procesal penal. En tal sentido la vigencia de la reparación civil en el proceso penal dependerá del plazo de prescriptorio de la acción penal, vale decir del plazo extraordinario de prescripción de la acción penal, tal como así lo establece la normativa antes citada, así entonces se tiene que si la acción penal se extinga por prescripción consecuentemente la acción civil fenecerá.

\subsection{Jurisprudencia sobre la vigencia de la reparación civil en la prescripción de la acción penal}

Respecto a esta variable se tiene que conforme a lo señalado por el (Tribunal Constitucional en la sentencia recaída en el expediente $\mathrm{N}^{\circ} 1205-2005-\mathrm{HC} /$ TC, 2005) indica que: 6 . la prescripción desde un punto de vista general, es la institución jurídica mediante la cual, por el trascurso del tiempo, la persona adquiere derechos o se libera de obligaciones. Y desde la óptica penal, es una causa de extinción de la responsabilidad criminal fundada en la acción del tiempo sobre los acontecimientos humanos o la renuncia del Estado al ius punendi, en razón de que el tiempo transcurrido borra los efectos de la infracción, existiendo apenas memoria social de la misma. 11. De acuerdo con lo establecido en le ley penal material, la prescripción es un medio para liberarse de las consecuencias penales y civiles de una infracción penal o una condena penal por efecto del tiempo y en las condiciones exigidas por la ley.

Así mismo señala (San Martín Castro, 2012) la Jurisprudencia Suprema, ha considerado que si se declara la prescripción de la acción penal o si se absuelve al imputado no cabe que este responda civilmente. 


\section{WILFREDO CHURA SOTOMAYOR}

Entonces desde una perspectiva general, la prescripción es una institución jurídica mediante la cual una persona se libera de obligaciones o adquiere derechos por el transcurso del tiempo. En el ámbito penal, se sostiene que la prescripción supondría la invalidación, por el transcurso del tiempo, tanto del interés represivo y de la alarma social producida por el hecho delictivo, como la extinción de los efectos de este.

Para nuestro (Tribunal Constitucional Sentencia del Exp. N¹80-2005-HC, 2005) La prescripción desde un punto de vista general, es la institución jurídica mediante el cual, por el transcurso del tiempo, la persona adquiere derechos o se libra de obligaciones. Y, desde la óptica penal, es una causa de extinción de la responsabilidad criminal fundada en la acción del tiempo sobre los acontecimientos humanos o la renuncia del Estado al ius puniendi, en razón de que el tiempo transcurrido borra los efectos de la infracción, existiendo apenas memoria social de la misma.

La (Corte Suprema Acuerdo Plenario 8-2008/CJ-116) define la prescripción de la acción penal puede definirse como el transcurso del tiempo que extinguen la persecución de un delito. No obstante, en un plano más técnico se le identifica como la perdida, por parte del Estado, de la facultad de ejercitar en un caso concreto el ius puniendi otros conceptos de prescripción aluden más bien a los efectos que aquella produce sobre la antijurícidad de un hecho punible y sobre la culpabilidad o responsabilidad de su autor señalándose que aquella tendría la condición de circunstancias que invalida el delito y sus consecuencias.

En cuanto a su fundamento constitucional, se sostiene que se encontraría tanto en los derechos a la presunción de inocencia y a un juicio sin dilaciones indebidas como el principio de prohibición de indefensión, todos ellos en conexión con el principio de seguridad jurídica. Es decir, mediante la prescripción se limita la potestad punitiva del Estado, dado que se extingue la posibilidad de investigar un hecho criminal y, con él, la responsabilidad del supuesto autor o autores del mismo (Tribunal Constitucional Sentencia del Proceso de Habeas Corpus Exp. 7451-2005-PHC/TC fundamento.04).

Como se ha podido apreciar las consecuencias de la prescripción de la acción penal, tal como lo ha establecido el Tribunal Constitucional en su jurisprudencias, así como la Corte Suprema indican que también si afectaría a la reparación civil toda vez que la prescripción borra los efectos de la acción delictiva ya sean penales o civiles en tal razón la jurisprudencia indica que la vigencia de la reparación civil está sujeta a la prescripción de la acción penal cuando esta se acumule dentro del proceso penal.

\subsection{Criterios y fundamentos}

(Asencio Mellado, 2010)manifiesta que respecto a los criterios y fundamentos del pronunciamiento de la reparación civil cuando la acción penal ha prescrito resulta que la reparación civil que se ventila en el proceso penal por causa de un hecho ilícito de apariencia delictiva es de naturaleza privada o civil. Afirmar lo contrario, esto es que la reparación que se desarrolla en el proceso penal es publica o en todo caso mixta, seria admitir que existen dos tipos de responsabilidades civiles, lo cual resulta equivocado, pues la responsabilidad civil es una en todo el ordenamiento jurídico, independientemente de donde se encuentre recogida las reglas específicas que busca hacerla efectiva y en tanto se basa para su configuración en la existencia de un daño y no en la producción de un delito, debe ser considerada de naturaleza civil.

(Sánchez Jordán, 1991)Indica que debe entenderse que la responsabilidad civil que se ventila en el proceso penal no es en puridad ex delito, sino - al igual que cualquier responsabilidad civil en general - ex daño, es decir no nace del delito, sino del daño ocasionado por actos ilícitos, acto que además pueden estar tipificados como delito o falta. De ello se colige que existe delito que no acarrea daños, razón por lo cual será imposible plantear una acción civil de reparación por un daño inexistente, aunque el delito efectivamente se haya concretizado. Para nuestras (Salas Penales Permanente y Transitorio de la Corte Suprema de Justicia de la Republica, 2006)señalaron: Así pues, en la mayoría de delitos de peligro no existiría la causación de un daño, como también se puede encontrar ausente el daño en algunas formas de tentativa. En estos casos, aunque exista responsabilidad penal no existirá - por la ausencia de daño - responsabilidad civil. En este sentido, también se ha pronunciado la Corte Suprema de nuestro país cuando ha dejado dicho que: «la reparación civil, que legalmente define el ámbito del objeto civil del proceso penal y está regulada por el artículo 93 del Código Penal, desde luego, presenta elementos diferenciados de la sanción penal; existen notas propias, finalidades y criterios de imputación distinto entre responsabilidad penal y responsabilidad civil, aun cuando comparte un mismo presupuesto: el acto ilícito causado por un hecho antijurídico, a partir del cual surge las diferencias respecto de su regulación jurídica 
y contenido entre el ilícito penal y el ilícito civil. Así las cosas, se tiene que el fundamento de la responsabilidad civil, que origina la obligación de reparar, es la existencia de un daño civil causado por un ilícito penal, el que obviamente no puede identificar con ofensa penal-lesión o puesta en peligro de un (bien) jurídico protegido, cuya base se encuentra en la culpabilidad del agente-[la causa inmediata de la responsabilidad penal y la civil ex delito, infracción/ daño, es distinta]; el resultado dañoso y el objeto sobre el que recae la lesión son distintos, como refiere la Corte Suprema: «Con independencia de su ubicación formal, la naturaleza jurídica de la reparación civil es incuestionablemente civil, y que aun cuando exista la posibilidad legislativamente admitida de que un Juez Penal pueda pronunciarse sobre el daño y su atribución, y en su caso determinar el quantum indemnizatorio - acumulación heterogenia de acciones - ello responde de manera exclusiva a la aplicación del principio de economía procesal. (Gimeno Sendra, 2010) sostiene, que el fundamento de la acumulación de la acción civil a la penal derivada del delito es la economía procesal, toda vez que dicho sistema permite discutir y decidir en un solo proceso, tanto la pretensión penal, como la pretensión civil resarcitoria que pudiera surgir como consecuencia de los daños cometidos por la acción delictuosa y que, de ser decidida con absoluta separación en un proceso civil produciría mayores gastos y dilaciones al perjudicado por el delito, debido a la onerosidad, lentitud e ineficacia de nuestro ordenamiento procesal civil, (Guillermo Bringas, 2011)manifiesta que, debemos precisar que esta acumulación, considerando la naturaleza jurídica de la reparación civil y realizando una interpretación sistemática del ordenamiento jurídico vigente, no es obligatorio, sino que dependerá de la voluntad del agraviado. En este sentido, procederá la acumulación, siempre y cuando, el agraviado así lo decida, constituyéndose, para ese efecto, en actor civil. Es decir, la posibilidad de acumular las acciones debe entenderse solo como eso: una posibilidad, nunca como un acto obligatorio, por ello es posible acudir a otra vía distinta a la penal con la finalidad de que el agraviado o perjudicado se procure la reparación civil correspondiente. Además el $\mathrm{CPP}^{2}$ de 2004 en su artículo 11 inciso 1, acorde con lo dicho, prescribe que «El perjudicado por el delito podrá ejercer la acción civil en el proceso penal o ante el orden jurisdiccional». Lo que se debe concordar con el artículo 106 del mismo cuerpo normativo, que a la letra establece: «La constitución en actor civil impide que se presente demanda indemnizatoria en la vía extra-penal. El actor

2 En adelante entiéndase como: CPP (Código Procesal Penal) civil que se desiste como tal antes de la acusación fiscal no está impedido de ejercer la acción indemnizatoria en la otra vía». Por otro lado la falta de imposición de una pena o el archivamiento del proceso no debe traer como consecuencia relevar al juez penal de emitir un pronunciamiento respecto de la reparación civil en caso de estar acreditado el daño. El artículo 12, inciso 3 del Código Procesal Penal de 2004 establece que la sentencia absolutoria o el sobreseimiento del proceso no impedirán al órgano jurisdiccional pronunciarse sobre la responsabilidad civil derivado del hecho punible.

Los criterios y fundamentos respecto al pronunciamiento de la reparación civil cuando la acción penal ha prescrito no son fundamentos sólidos pues no indican cual sería el plazo aplicable a la acción civil resarcitoria, toda vez que solo se indica que la acción civil en el proceso penal es proveniente del daño, mas no de la responsabilidad del delito, así mismo se basa en que el artículo 12 inciso 3 del Código procesal faculta el pronunciamiento de la reparación civil dentro del proceso penal, en tal sentido lo establecido por sentencia del tribunal constitucional, respecto a los efectos de la prescripción de la acción penal son más sólidos, pues esta manifiesta que si afecta a la reparación civil, y consecuentemente no se podría pronunciarse sobre la misma.

\section{RESULTADOS}

\subsection{El órgano jurisdiccional penal no puede aplicar el artículo 12 inciso 3 respecto a la reparación civil cuando la acción penal ha prescrito}

Según los análisis realizados respecto a la prescripción esta impide que el Estado ejerza una de sus funciones más importantes a saber, en cuanto a la materialización del ius puniendi estatal, por la desidia del mismo estado quien está a cargo de la persecución y sanción penal, pues el imputado no puede estar sometido a la persecución perpetua más aún que la prescripción es una institución jurídica mediante la cual una persona se libera de obligaciones o adquiere derechos por el transcurso del tiempo. Y en el ámbito penal, se sostiene que la prescripción supondría la invalidación, por el transcurso del tiempo, tanto del interés represivo y de la alarma social producida por el hecho delictivo, como la extinción de los efectos de este, en tal razón no se podría hablar de una reparación civil cuando la acción penal se ha extinguido por prescripción.

Nuestro (Tribunal Constitucional realiza una definición en la sentencia recaída en el expediente $\mathrm{N}^{\circ}$ 


\section{WILFREDO CHURA SOTOMAYOR}

1205-2005-HC/TC )indica que: De acuerdo con lo establecido en le ley penal material, la prescripción es un medio para liberarse de las consecuencias penales y civiles de una infracción penal o una condena penal por efecto del tiempo y en las condiciones exigidas por la ley. por consiguiente, la prescripción igualmente constituye un supuesto de extinción de la acción penal y consecuentemente de la acción civil tal como así lo sostiene el tribunal constitucional en la sentencia antes mencionada, es decir, mediante la prescripción se limita la potestad punitiva del Estado, dado que se extingue la posibilidad de investigar un hecho criminal $\mathrm{y}$, con él, la responsabilidad del supuesto autor o autores del mismo así como de las consecuencias civiles, vale decir que si en un proceso penal se declara prescrita la acción penal, en tal razón el Juez no podrá pronunciarse respecto a la reparación civil, y en consecuencia no se podría aplicar el artículo 12 inciso 3 del CPP, que indica que la sentencia absolutoria o el auto de sobreseimiento no impedirá al órgano jurisdiccional pronunciarse sobre la reparación civil derivada del hecho punible válidamente ejercida toda vez que existe por medio una causal de extinción de la acción penal que es la prescripción y más aun teniendo como consecuencia de esta la extinción de la responsabilidad penal y sus consecuencias de la misma, y es así la jurisprudencia suprema, además ha considerado que si declara la prescripción de la acción penal o si se absuelve al imputado no cabe que este responda civilmente.

Queda entonces demostrado que el órgano jurisdiccional penal no puede aplicar el artículo 12 inciso 3 respecto a la reparación civil cuando la acción penal ha prescrito, puesto que la prescripción de la acción penal si afecta a la reparación civil, así mismo por el principio de especialidad respecto al plazo de prescripción de la acción civil seria el plazo prescriptorio extraordinario de la acción penal, en consecuencia queda demostrado nuestra hipótesis plantea.

4.2. La regulación legal de la prescripción de la acción penal establece que esta afecta también a la reparación civil en el proceso penal impidiendo que el órgano jurisdiccional se pronuncie sobre ella, por haberse extinguido la misma.

Como se ha visto en el estudio de la extinción de la reparación civil estas nos llevado a considerar las normas específicas que se deben tomar en cuenta para analizar la regulación legal respecto al plazo de prescripción aplicable a la reparación civil, del mismo son los artículos 2001, inciso 4 del Código Civil y el articulo 100 del Código Penal, el primero de los artículos citados (artículo 2001, inciso 4 del Código Civil) establece que prescribe «salvo disposición diversa de la ley: (...) 4. A los dos años, la acción de anulabilidad, la acción de revocatoria, la que proviene de pensión alimenticia, la acción indemnización por responsabilidad extracontractual. A su vez el artículo 100 del Código Penal establece que la «acción civil derivada del hecho punible no extingue mientras subsista la acción penal» En tal razón lo primero que debemos señalar, es que el termino extinción a que hace referencia el citado artículo del Código Penal no hace referencia a la extinción de la acción civil en general, sino solamente a la extinción por prescripción de esta cuando provenga de un hecho punible, para ser más exacto de un ilícito de apariencia delictiva.

(Gálvez Villegas T. A., 2005)refiere que de acuerdo a ello, se tiene que el artículo 100 del Código Penal regula que la acción civil solo se extinguirá por prescripción cuando la acción penal se extinga igualmente por prescripción, de modo que debe descartarse aquella interpretación literal del referido artículo, que entiende que si la acción civil no se extingue mientras subsiste la acción penal, entonces a contrario sensu, una vez extinguida la acción penal, la acción civil también se extinguirá, pues la acción penal puede extinguirse por amnistía, muerte del imputado, entre otras causales, lo cual no implica la extinción de la acción civil, bajo esa perspectiva, entonces se tiene que a efectos de la acción civil por responsabilidad extracontractual proveniente de una conducta delictiva, no es aplicable el inciso 4 del artículo 2001 del Código Civil, toda vez que por el principio de especialidad e aplicación de la ley hace aplicable el artículo 100 del Código Penal, en tal razón queda comprobado nuestra hipótesis plantea y más aun con los estudios de la legislación comparada de Colombia en su Código penal en el artículo 98. Que indica respecto a la Prescripción. La acción civil proveniente de la conducta punible, cuando se ejercita dentro del proceso penal, prescribe, en relación con los penalmente responsables, en tiempo igual al de la prescripción de la respectiva acción penal. En los demás casos, se aplicarán las normas pertinentes de la legislación civil como se puede apreciar el Código penal colombiano hace depender la subsistencia de la reparación civil de la prescripción de la respectiva acción penal, cuando se ejercita dentro del proceso penal, todo esto nos permite afirmar que la regulación legal de la prescripción de la acción penal establece que esta afecta también a la reparación civil en el proceso penal impidiendo que el órgano jurisdiccional se pronuncie sobre ella, por haberse extinguido la misma. 
4.3. Las sentencias emitidas por el órgano jurisdiccional son contrarias a la regulación respecto a la reparación civil cuando la acción penal ha prescrito

Por medio de la tabla (1), se presentan los expedientes que han sido materia de análisis y estudio en la investigación, mostrándose los datos que importan para su desarrollo y resaltando la información relevante que permite dar certeza de la comprobación de la hipótesis planteada.

Tabla 1: Sentencias emitidas por el órgano jurisdiccional contrarias a la regulación respecto a la reparación civil cuando la pena ha prescrito*

\begin{tabular}{|c|c|c|}
\hline POSTURA & $\begin{array}{l}\text { CANTIDAD DE } \\
\text { EXP. }\end{array}$ & PORCENTAJE \\
\hline $\begin{array}{l}\text { Afavor delareparacion ovil arandolaacion } \\
\text { pend prescibe }\end{array}$ & 13 & $13 \%$ \\
\hline $\begin{array}{l}\text { En cortra delareparacion ovil auando laacion } \\
\text { pena haprescito }\end{array}$ & 2 & $2 \%$ \\
\hline Toda & & $15 \%$ \\
\hline
\end{tabular}

*Fuente: Consolidado de la revisión de Expedientes del, Tercer Juzgado Unipersonal Penal de la Corte Superior de Justicia de Puno en el año 2011.

"Elaboración: Propia.

De acuerdo a la tabla 1 , se desprende que el $13 \%$ de expedientes tramitados en el Tercer Juzgado Unipersonal de la Corte Superior de Justicia de Puno indican la imposición de una reparación civil cuando la acción penal ha prescrito realizando la aplicación del artículo 12 inciso 3 del Código Procesal Penal, así también se visualiza el $2 \%$ señala de los expedientes analizados se tiene que el Juzgado Unipersonal en lo Penal no se ha pronunciado respecto a la pretensión resarcitoria vale decir a la reparación civil, puesto que en el proceso el agraviado no sea constituido en parte. Entonces, se puede colegir que en la mayoría de expedientes tramitados se contraviene el artículo 2001, inciso 4 del Código Civil establece que prescribe «salvo disposición diversa de la ley, en el inciso 4. A los dos años, la acción indemnización por responsabilidad extra contractual, a su vez el artículo 100 del Código Penal establece que la «acción civil derivada del hecho punible no extingue mientras subsista la acción penal» en tal razón lo primero que debemos señalar, es que el termino extinción a que hace referencia el citado artículo del Código Penal hace referencia a la extinción de la acción civil a la extinción por prescripción de esta cuando provenga de un hecho punible, para ser más exacto de un ilícito de apariencia delictiva, de acuerdo a ello, se tiene que el artículo 100 del Código Penal regula que la acción civil solo se extinguirá por prescripción cuando la acción penal se extinga igualmente por prescripción, bajo esa perspectiva, entonces se tiene que a efectos de la acción civil por responsabilidad extracontractual proveniente de una conducta delictiva, no es aplicable el inciso 4 del artículo 2001 del Código Civil, toda vez que por el principio de especialidad de aplicación de la ley hace aplicable el artículo 100 del Código Penal.

De esta forma se tiene que si producido el ilícito penal generador de daño, transcurren más de dos años (inciso 4 del artículo 2001 del Código Civil) sin que interrumpa la prescripción de la acción civil, ello no la extingue, pues el plazo de prescripción aplicable es de la acción penal (artículo 100 del Código Penal). Solo si transcurre el plazo de prescripción extraordinaria de la acción penal (artículo 83 in fine del Código Penal) ininterrumpidamente la acción penal y, con ella la civil, fenecerán. En tal sentido queda demostrado nuestra hipótesis de que las sentencias emitidas por el órgano jurisdiccional son contrarias a la regulación respecto a la reparación civil cuando la acción penal ha prescrito, como se puede apreciar del cuadro antes expuestos.

Es necesario la realización de un Acuerdo Plenario que delimite los alcances de la vigencia de la reparación civil cuando la acción penal haya prescrito, estableciendo como doctrina jurisprudencial su extinción conjunta con la acción penal.

Finalmente respecto a la última hipótesis está demostrado que no se tiene un solo criterio de aplicación de los alcances y límites de la reparación civil cuando la acción penal ha prescrito, y en tal sentido proponemos la celebración de un acuerdo plenario que delimite los alcances y la vigencia de la reparación civil cuando la acción penal haya prescrito estableciendo como doctrina jurisprudencial su extinción conjunta con la prescripción de la acción penal.

\section{CONCLUSIONES}

Queda demostrado que el órgano jurisdiccional penal no puede pronunciarse respecto a la reparación civil cuando la acción penal ha prescrito, conforme del análisis realizado, se tiene que la prescripción es una de las formas de extinción de la acción penal establecidas en el Código Penal y reiterada en el Código Procesal Penal, y es más, definiendo a la prescripción como un medio de liberarse de las consecuencias penales y civiles de una infracción penal o una condena penal por efecto del tiempo y en las condiciones 


\section{WILFREDO CHURA SOTOMAYOR}

exigidas por la Ley para que opere esta excepción, el factor predominante es el transcurso del tiempo.

La regulación en nuestro país sobre la extinción de la acción penal por prescripción afecta también a la acción civil, así mismo tomándose en cuenta la legislación comparada correspondiente a Colombia y España, se tiene que la vigencia de la reparación civil está sujeta a la extinción de la acción penal.

Del análisis de sentencias, se tiene que los jueces penales en una parte señalan en sus sentencias que la responsabilidad penal y la responsabilidad civil, tienen naturaleza jurídica distinta, puesto que la primera puede extinguirse por prescripción, en tanto la responsabilidad civil subsiste, porque ya se produjo el daño e ingresan al análisis de la reparación civil indican que es un mecanismo retributivo, porque el sujeto activo de un injusto penal repara el hecho cometido en atención al deterioro de los bienes jurídicos causados a la parte agraviada, y está orientado a tratar de satisfacerla. Por otro lado otro parte de los jueces señalan que la prescripción afecta a la vigencia de la reparación civil y por lo tanto no se tendría que pronunciarse respecto a la reparación civil si la acción penal prescribe.

Está demostrado que no existen medidas y criterios para una adecuada interpretación de la regulación sobre la vigencia de la Reparación Civil en el Proceso Penal cuando la acción penal ha prescrito, en tal sentido es necesario realizar un acuerdo plenario que establezca los lineamientos para una correcta interpretación y aplicación sobre la Reparación Civil derivada del delito.

\section{SUGERENCIAS}

Teniendo en consideración que la prescripción tiene como las razones de seguridad de orden social y paz social, pues para el derecho le interesa particularmente liquidar ciertas situaciones inestables, impidiendo estas que pueden ser materia de revisión después de pasado cierto tiempo. De esta manera, buscar dar certeza a los derechos adquiridos como producto del paso del tiempo, además, teniendo en consideración que un sistema penal respetuoso de la dignidad humana, orientado en cumplir un rol político criminal humanista acorde con fines resocializadores, debe diseñar y adoptar medidas que vayan acorde con el fin específico de la persecución penal, más allá de las pretensiones de carácter privado en tal razón: Se debiera celebrar un acuerdo plenario que delimite los alcances de la vigencia de la reparación civil cuando la acción penal ha prescrito, estableciéndose esta como doctrina jurisprudencial su extinción conjunta con la acción penal por prescripción y los lineamientos de aplicación del artículo 12 inciso 3 del Código Procesal Penal.

\section{BIBLIOGRAFÍA}

Asencio Mellado, J. M. (2010). La accion civil en el proceso penal. Lima: EDITORES. Lima, Perú: ARA.

Castillo Alva, J. L. (2001). Las consecuencias juridicoeconomicas del delito. Lima: IDEMSA.

Corte Suprema Acuerdo Plenario 8-2008/CJ-116. (s.f.). Gálvez Villegas, T. A. (2005). La reparacion civil en el proceso penal. Lima: IDEMSA.

Gálvez Villegas, T. A. (2012). Posibilidad de recurrir a la via civil luego de concluido el proceso penal. Cuando el agraviado se ha constituido en actor civil y su pretencion ha sido amparada. . Lima: Gaceta Juridica.

Gimeno Sendra, V. (2010). Manual de Derecho Procesal Penal. . Madrid: COLEX.

Guillermo Bringas, L. G. (2011). La reparacion civil en el proceso penal. aspectos sustantivos y procesales. . Lima: Pacifico Editores.

Peña Cabrera Freyre, A. (2010). Naturaleza jurídica de la reparacin civil ex delito. Lima: Gaceta Jurídica.

Revilla LLaza, P. (2009). Precisiones sobre la prescripcion de la accion civil reparatoria sustentada en el daño ex delicto. Lima: Gaceta Juridica.

Roy Freyre, L. E. (1979). Causas de Extinción de la Acción Penal y de la Pena. (Primera ed.). Lima, Peu: Grijiley E.I.R.L.

Salinas Siccha, R. (2009). La extinción de la accion civil derivada del hecho punible. . Lima: Gaceta Juridica.

San Martín Castro, C. E. (2012). Estudios de Derecho Procesal Penal. Lima : Grijley E.I.R.L.

Sánchez Jordán, M. E. (1991). Problemas de la llamada responsabilidad civil por delito. Navarra-España: Revista Juridica de Navarra .

Salas Penales Permanente y Transitorio de la Corte Suprema de Justicia de la Republica. (2006)

Tribunal Constitucional realiza una definición en la sentencia recaída en el expediente $N^{\circ} 1205-2005-H C / T C$ . (s.f.).

Tribunal Constitucional Sentencia del Proceso de Habeas Corpus Exp. 7451-2005-PHC/TC fundamento.04. (s.f.). Tribunal Constitucional en la sentencia recaída en el expediente $N^{o}$ 1205-2005-HC/TC. (2005). Lima.

Tribunal Constitucional Sentencia del Exp. $N^{\circ} 180-2005$ HC. (2005).

Villegas Paiva, E. A. (2010). Principios y presupuestos de la prision preventiva en el nuevo codigo procesal Penal. Lima: Gaceta Juridica.

Villegas Paiva, E. A. (2013). El agraviado y la reparación civil en el nuevo código procesal penal (Primera ed.). Lima, Peru: Gaceta Juridica. 